\title{
Predicting Future Forest Ranges Using Array-based Geospatial Semantic Modelling
}

\author{
Elise Mulder Osenga ${ }^{1}$ \\ 1 Science Writer, Earthzine
}

This manuscript has been accepted for publication in IEEE Earthzine.

IEEE Earthzine 2014 Vol. 7 Issue 2, (to appear)

$2^{\text {nd }}$ quarter theme. Geospatial Semantic Array Programming

\begin{abstract}
Studying the impacts of climate change requires looking at a multitude of variables across a broad range of sectors $[1,2]$. Information on the variables involved is often unevenly available or offers different uncertainties [3, 4], and a lack of uniform terminology and methods further complicates the process of analysis, resulting in communication gaps when research enterprises span different sectors. For example, models designed by experts in one given discipline might assume conventions in language or oversimplify cross-disciplinary links in a way that is unfamiliar for scientists in another discipline.

Geospatial Semantic Array Programming (GeoSemAP) offers the potential to move toward overcoming these challenges by promoting a uniform approach to data collection and sharing [5]. The Joint Research Centre of the European Commission has been exploring the use of geospatial semantics through a module in the PESETA II project (Projection of economic impacts of climate change in sectors of the European Union based on bottom-up analysis).
\end{abstract}

The work of more than 40 scientists from 12 teams, the PESETA II project is intended to provide the European Commission (and other stakeholders) with an integrated analysis of the potential impacts of climate change in Europe [6]. This analysis takes the form of quantitative models that cover 10 main topics: agriculture, energy, river floods, droughts, forest fires, transport infrastructure, coasts, tourism, habitat suitability of forest tree species, and human health. The motivation behind these models is to assist adaptation plans for climate change impacts to Europe, while highlighting the uncertainties inherent in integrated assessment and in tipping-point phenomena [7, 8, 9]. 
bioRxiv preprint doi: https://doi.org/10.1101/009597; this version posted October 6, 2014. The copyright holder for this preprint (which was not certified by peer review) is the author/funder. All rights reserved. No reuse allowed without permission.

IEEE Earthzine 2014 Vol. 7 Issue 2 - Mulder Osenga: Predicting Future Forest Ranges Using Array-based Geospatial Semantic Modelling

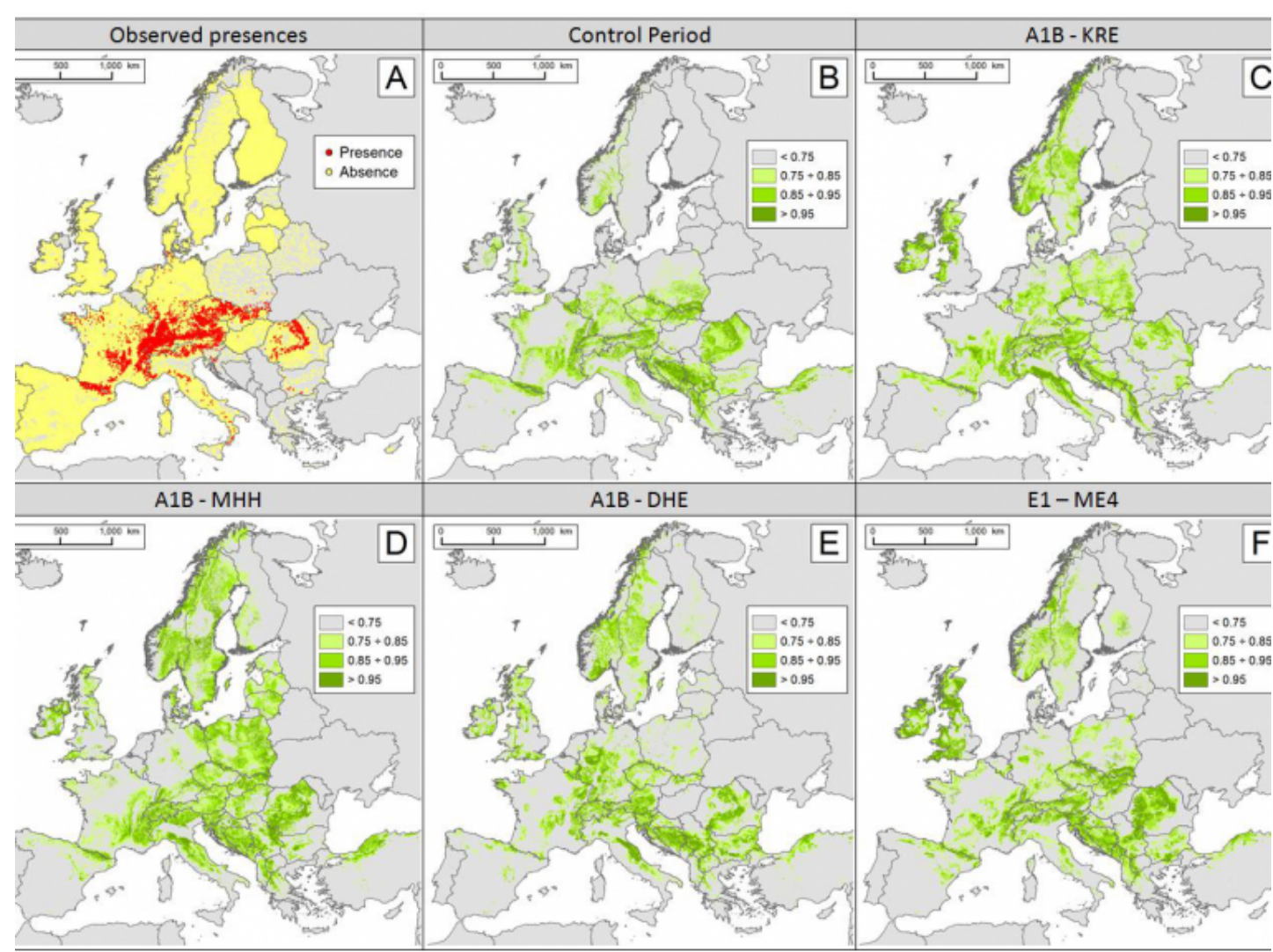

Figure 1: The Maximum Habitat Suitability based on the Relative Distance Similarity algorithm (RDS-MHS) estimated for Abies alba in the control period (B) and the climate change scenarios $A 1 B(C, D, E)$ and E1 (F). Image Credit: Ciscar et al., 2014 [6], European Union, 2014.

The section on habitat suitability for tree species focuses on the European silver fir and can be used as an example of how the PESETA project works. The habitat suitability study incorporates data on existing tree distribution, bioclimatic factors, topography, and solar irradiation using a method known as the Relative Distance SimilarityMaximum Habitat Suitability Method (RDS-MHS).

The RDS technique calculates similarity between current geo-climactic conditions for a given area (such as

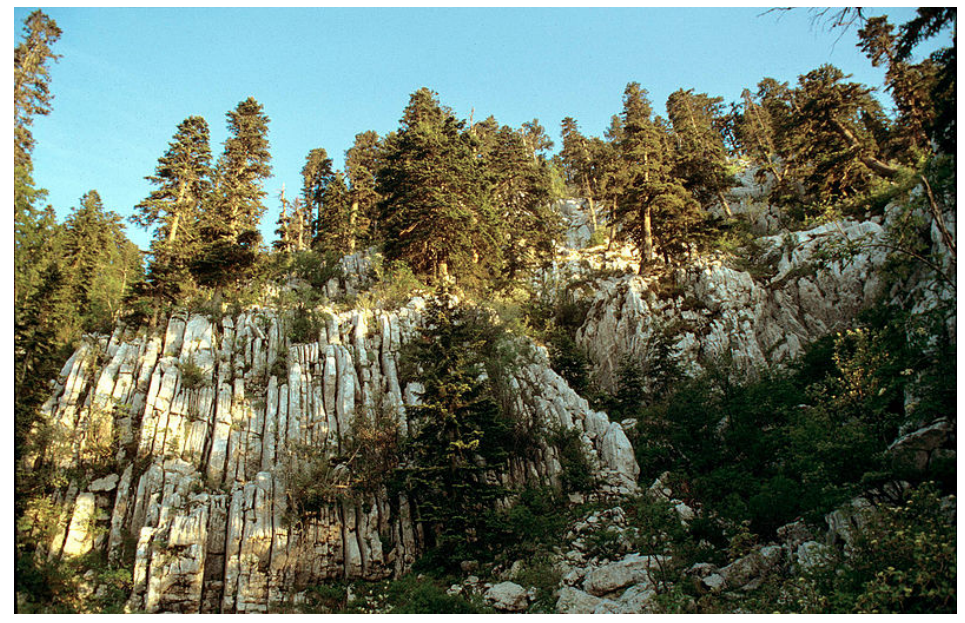

Dinaric calcareous Karst block fir forest in Orjen. Image Credit: Pavle Cikovac, Wikimedia Commons. Europe) and potential conditions for the same area likely under such climate scenarios as a 3.5 degree Celsius (A1B scenarios) or a 2 degree Celsius increase (E1 scenario). 
IEEE Earthzine 2014 Vol. 7 Issue 2 - Mulder Osenga: Predicting Future Forest Ranges Using Array-based Geospatial Semantic Modelling

To create such model, the RDS software is programmed to define regions where silver fir currently lives or could live: the maximum habitat suitability (MHS) of the tree species. Next, the model uses this program to describe where the species could survive in the future, based on habitat predictions. The data are then used to create an index that represents the areas of new, lost, and stable habitat suitable under future climate conditions. These data could be applicable to planners by indicating areas where introduced silver fir would be most likely to survive.

The index also offers a projection of natural shifts in silver fir occurrence. Areas that have been calculated to have a high level of dissimilarity to current conditions may see a loss. By contrast, areas that are at a higher elevation or north of current populations of silver fir may see an increase or introduction of the species. Therefore, an index such as that of PESETA II could be valuable in helping land managers and others to determine which species are most likely to survive under future conditions and which may be futile to plant or restore.

The index is, however, limited in its efficacy as a management tool by two primary factors. First, the model assumes unlimited dispersal capacity by the trees under consideration. It does not account for actual limits to species migration. Second, since the models focus on climate response at a species, rather than an ecosystem level, complex habitat changes associated with changes in keystone species are not taken into account. For both of these reasons, the models tend to be conservative in their estimates of range loss.

In addition to its use for projecting future forest conditions, RDS has been applied to other environmental problems, from estimating soil erosion at the pan-European scale $[10,11]$ to deriving a fuzzy map of the Food and Agricultural Organization (FAO) ecological zones in Europe [12] and modelling susceptibility to landslides at the catchment scale [13].

Although the habitat suitability index and other RDS outputs are limited in their ability to forecast the future, they demonstrate a way of creating projects to help adaptation planning. The exact repercussions of climate change for local species and ecosystems remain uncertain, but by describing the maximum potential in future scenarios, models such as PESETA II can help planners to move forward.

\section{References}

[1] B. L. Turner, R. E. Kasperson, P. A. Matson, J. J. McCarthy, R. W. Corell, L. Christensen, N. Eckley, J. X. Kasperson, A. Luers, M. L. Martello, C. Polsky, A. Pulsipher, and A. Schiller, "A framework for vulnerability analysis in sustainability science," Proceedings of the National Academy of Sciences, vol. 100, no. 14, pp. 8074-8079, 2003. doi: 10.1073/pnas.1231335100

[2] K. L. O'Brien and R. M. Leichenko, "Double exposure: assessing the impacts of climate change within the context of economic globalization," Global Environmental Change, vol. 10, no. 3, pp. 221-232, 2000. doi: 10.1016/s0959-3780(00)00021-2

[3] M. S. Torn and J. Harte, "Missing feedbacks, asymmetric uncertainties, and the underestimation of future warming," Geophysical Research Letters, vol. 33, no. 10, p. n/a, 2006. doi: 10.1029/2005g1025540

[4] M. Maslin and P. Austin, "Uncertainty: Climate models at their limit?" Nature, vol. 486, no. 7402 , pp. 183-184, 2012. doi: 10.1038/486183a

[5] D. de Rigo, Semantic Array Programming with Mastrave - Introduction to Semantic Computational Modelling, 2012. [Online]. Available: http://mastrave.org/doc/MTV-1. 012-1/ 
IEEE Earthzine 2014 Vol. 7 Issue 2 - Mulder Osenga: Predicting Future Forest Ranges Using Array-based Geospatial Semantic Modelling

[6] J.-C. Ciscar, L. Feyen, A. Soria, C. Lavalle, F. Raes, M. Perry, F. Nemry, H. Demirel, M. Rozsai, A. Dosio, M. Donatelli, A. K. Srivastava, D. Fumagalli, S. Niemeyer, S. Shrestha, P. Ciaian, M. Himics, B. Van Doorslaer, S. Barrios, N. Ibáñez, G. Forzieri, R. Rojas, A. Bianchi, P. Dowling, A. Camia, G. Libertà, J. San-Miguel-Ayanz, D. de Rigo, G. Caudullo, J. I. Barredo, D. Paci, J. Pycroft, B. Saveyn, D. Van Regemorter, T. Revesz, T. Vandyck, Z. Vrontisi, C. Baranzelli, I. Vandecasteele, F. Batista e Silva, and D. Ibarreta, Climate Impacts in Europe - The JRC PESETA II project, ser. EUR - Scientific and Technical Research, J. C. Ciscar, Ed. Publications Office of the European Union, 2014, vol. 26586, 155 pp. doi: 10.2791/7409

[7] T. M. Lenton and J.-C. Ciscar, "Integrating tipping points into climate impact assessments," Climatic Change, vol. 117, no. 3, pp. 585-597, 2013. doi: 10.1007/s10584-012-0572-8

[8] F. Biermann, K. Abbott, S. Andresen, K. Bäckstrand, S. Bernstein, M. M. Betsill, H. Bulkeley, B. Cashore, J. Clapp, C. Folke, A. Gupta, J. Gupta, P. M. Haas, A. Jordan, N. Kanie, T. Kluvánková-Oravská, L. Lebel, D. Liverman, J. Meadowcroft, R. B. Mitchell, P. Newell, S. Oberthür, L. Olsson, P. Pattberg, R. Sánchez-Rodríguez, H. Schroeder, A. Underdal, S. Camargo Vieira, C. Vogel, O. R. Young, A. Brock, and R. Zondervan, "Navigating the anthropocene: Improving earth system governance," Science, vol. 335, no. 6074, pp. 1306-1307, 2012. doi: 10.1126/science.1217255

[9] T. M. Lenton, H. Held, E. Kriegler, J. W. Hall, W. Lucht, S. Rahmstorf, and H. J. Schellnhuber, "Tipping elements in the earth's climate system," Proceedings of the National Academy of Sciences, vol. 105, no. 6, pp. 1786-1793, 2008. doi: 10.1073/pnas.0705414105

[10] C. Bosco, D. de Rigo, O. Dewitte, and L. Montanarella, "Towards the reproducibility in soil erosion modelling: a new pan-European soil erosion map," in Wageningen conference on applied soil science : 'Soil Science in a Changing World', S. D. Keesstra and G. Mol, Eds. Wageningen University, 2011. doi: 10.6084/m9.figshare.936872, arXiv:1402.3847

[11] C. Bosco, D. de Rigo, O. Dewitte, J. Poesen, and P. Panagos, "Modelling soil erosion at European scale: towards harmonization and reproducibility," Natural Hazards and Earth System Sciences Discussions , vol. 2, no. 4, pp. 2639-2680, 2014. doi: 10.5194/nhessd-22639-2014

[12] D. de Rigo, J. I. Barredo, L. Busetto, G. Caudullo, and J. San-Miguel-Ayanz, "Continentalscale living forest biomass and carbon stock: a robust fuzzy ensemble of ipcc tier 1 maps for Europe," IFIP Advances in Information and Communication Technology, vol. 413, pp. 271-284, 2013. doi: 10.1007/978-3-642-41151-9_26

[13] C. Bosco, D. de Rigo, T. A. Dijkstra, G. Sander, and J. Wasowski, "Multi-Scale robust modelling of landslide susceptibility: Regional rapid assessment and catchment robust fuzzy ensemble," IFIP Advances in Information and Communication Technology, vol. 413, pp. 321-335, 2013. doi: 10.1007/978-3-642-41151-9_31 